\title{
AÇÃO COLETIVA POLÍTICA E LUTA POR RECONHECIMENTO: A ATUAÇ̃̃O DA ASSOCIAÇÃO BRASILEIRA DE FAMÍLIAS HOMOTRANSAFETIVAS (ABRAFH) NA DEFESA DE OUTRAS MODALIDADES DE FAMÍLIAS
}

\author{
Elias Santos Serejo \\ Universidade Federal do Pará \\ eliassantos1001@gmail.com \\ Danila Cal \\ Universidade Federal do Pará \\ danilagentilcal23@gmail.com \\ Leandro Rodrigues Lage \\ Universidade Federal do Pará \\ leandrorlage@,gmail.com
}

\begin{abstract}
Resumo
A Associação Brasileira de Famílias Homotransafetivas (Abrafh) é uma entidade que luta pelo reconhecimento das populações cujo núcleo é formado por sujeitos LGBTQIA+. A instituição busca representar os anseios e expectativas dessas famílias em diferentes âmbitos sociais, assim como combater os desrespeitos e preconceitos advindos de um sistema heterossexista. Este trabalho busca compreender como a Abrafh mobiliza as dimensões do afeto e da solidariedade na luta política. Para isso, entrevistamos quatro representantes do primeiro conselho diretor. Por meio de uma análise qualitativa de conteúdo discursivo, pudemos compreender que a Abrafh, segundo os diretores, surge para acolher, defender e representar as famílias homoafetivas no sentido de tornar estes cidadãos emancipados e com direitos reconhecidos. Conclui-se que a instituição atua principalmente a partir da possibilidade de responder satisfatoriamente à necessidade que os sujeitos têm de desenvolverem conexões baseadas na confiança afetiva na continuidade da dedicação mútua.
\end{abstract}

Palavras-chave: Homoafetividade. Famílias. Luta por reconhecimento.

\section{COLLECTIVE ACTION POLICY AND FIGHT FOR RECOGNITION: THE ACTION OF THE BRAZILIAN ASSOCIATION OF HOMOTRANSAFECTIVE FAMILIES (ABRAFH) IN THE DEFENSE OF OTHER FAMILY MODALITIES}

\begin{abstract}
The Brazilian Association of Homotransfective Families (Abrafh) is an entity that fights for the recognition of populations whose nucleus is formed by LGBTQIA + people. The institution seeks to represent the desires and expectations of these families in different social spheres, as well as to combat the disrespect and prejudice arising from a heterosexist system. This paper seeks to understand how Abrafh mobilizes the dimensions of affection and solidarity in the political struggle. We interviewed four representatives of the first board. Through a qualitative analysis of discursive content, we could understand that Abrafh, according to the directors, arises to welcome, defend and represent homosexual families in order to make these citizens emancipated and with recognized rights. It is concluded that the institution acts mainly from the possibility of satisfactorily responding to the subjects' need to develop connections based on affective trust in the continuity of mutual dedication.
\end{abstract}

Keywords: Homoaffectivity. Families. Recognition struggle.

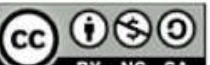




\section{INTRODUÇÃO}

Nas últimas três décadas, diversas iniciativas foram desenvolvidas na tentativa de institucionalizar lutas sociais, criar espaços de diálogo em ambientes formais e informais, além de instituir redes de apoio, solidariedade e afeto. Essas iniciativas, com especial atenção àquelas desenvolvidas por sujeitos que se identificam como lésbicas, gays, bissexuais, travestis, transexuais, queers 1, intersexuais, assexuais e outros (LGBTQIA+), e também de negros e mulheres, buscam, sobretudo, a desconstrução das normas reguladoras que operam sobre indivíduos em não-conformidade com a heteronorma patriarcal. Entre esses mecanismos de organização estão os associativismos, liderados por entidades da sociedade civil organizada que reúnem sujeitos com reivindicações coletivas específicas. A despeito das articulações contemporâneas e das formas difusas de atuação política que têm marcado a última década, em diversos países, muitas dessas associações ainda gozam de legitimidade diante de seus integrantes e simpatizantes, além de ocuparem um importante papel enquanto agentes de transformação e mobilização.

É nesse contexto que surge legalmente no mês de setembro de 2015 a Associação Brasileira de Famílias Homotransafetivas 2 (Abrafh), uma entidade da sociedade civil organizada que congrega famílias, com especial atenção aos grupos familiares cujo núcleo central seja formado por casais LGBTQIA+, e está no espectro da luta política pela diversidade sexual e de gênero que possui múltiplas nuances e pautas diversas (SIMÕES; FACCHINI, 2009). A reunião de indivíduos pertencentes a essa categoria social em coletivos, associações e grupos que buscam modificar as normas vigentes se dá, sobretudo, em virtude das situações de desrespeitos vivenciadas cotidianamente, tanto nas relações interpessoais quanto nos âmbitos institucionais.

Neste trabalho, buscamos investigar, a partir do aporte teórico da luta por reconhecimento (HONNETH, 2009; 2013), como a Abrafh mobiliza as dimensões do afeto e da solidariedade na luta política. Para isso, realizamos entrevistas semiestruturadas com quatro diretores do biênio 2015/2017 - a primeira diretoria da instituição. Como metodologia, desenvolvemos uma análise qualitativa de conteúdo discursivo (MENDONÇA, 2009) que consistiu na observação dos argumentos proferidos pelos diretores, assim como as justificações

\footnotetext{
${ }^{1}$ Do inglês, Queers é uma expressão que denota ao "estranho" e que foi apropriada pelo movimento como forma positiva de autoafirmação das diferenças.

${ }^{2}$ Famílias homoatransafetivas são famílias compostas por um núcleo formado por sujeitos LGBTQIA+. O termo foi alcunhado pela própria Abrafh.
} 
neles contidas, a partir da relação entre o que diziam e os três âmbitos do reconhecimento propostos por Honneth (2009). Dessa forma, a proposta teórica do autor foi operacionalizada em categorias analíticas que orientaram nossa compreensão dessas falas.

Assim, nosso objetivo é compreender como se configura a luta política da associação, à luz da base teórica fornecida por Honneth $(2009 ; 2013)$, com ênfase no modo como as experiências que afetam a integridade moral dos sujeitos podem desencadear conflitos sociais. Em primeiro lugar, será preciso situar as premissas da teoria do reconhecimento, tal como delineadas no principal trabalho de Honneth (2009) sobre o assunto. Em seguida, ressaltaremos as possibilidades de abordagem dos movimentos sociais a partir da teoria da luta por reconhecimento, entendida como uma teoria da justiça centrada nos conflitos sociais. Por fim, analisaremos as falas dos diretores da Abrafh a partir dos âmbitos do amor, direito e estima social. Ao final, destacamos, sobretudo, a importância da construção de relações de afeto, amizade e interesse mútuo como dimensão central da atuação política da instituição.

\section{BREVES NOTAS SOBRE A TEORIA DO RECONHECIMENTO}

A sistematização de uma teoria da luta por reconhecimento feita por Axel Honneth (2009) está fundamentada, principalmente, na compreensão da dimensão intersubjetiva da formação do self a partir dos trabalhos de George H. Mead e nas premissas de reconhecimento social encontradas nas obras do jovem Hegel. Para Honneth, os desrespeitos físicos, psicológicos e sociais podem atuar como força motriz de lutas sociais por reconhecimento. Por desrespeito, o autor entende não apenas injustiças que causam danos ou restringem liberdades, mas considera "aquele aspecto de um comportamento lesivo pelo qual as pessoas são feridas numa compreensão positiva de si mesmas, que elas adquirem de modo intersubjetivo" (HONNETH, 2009, p. 213).

A dimensão intersubjetiva do reconhecimento é, portanto, um elemento central da teoria do reconhecimento de Honneth (2009), segundo a qual o indivíduo se constitui como sujeito a partir da interação com o outro. De acordo com Honneth (2009), é por meio da intersubjetividade que cada um aprende a se referir a si mesmo e a reconhecer capacidades e propriedades que o constituem. Considerando que a autorrealização é adquirida a partir de uma autorrelação positiva com parceiros de interação, a experiência intersubjetiva deve estar em conformidade com os diferentes padrões de reconhecimento.

Honneth (2009) trabalha com três padrões de reconhecimento intersubjetivos: o do amor, o do direito e o da estima social. Da esfera do amor, ligada às relações primárias e às 
conexões emotivas fortes, advém a autorrealização pessoal oriunda de uma confiança em si mesmo. Nesse caso, há uma tensão entre autonomia e ligação com o outro - ou "simbiose e autoafirmação" - em que sujeitos se "confirmam mutualmente na natureza concreta de suas carências" (HONNETH, 2009, p. 160). Trata-se, segundo Honneth, de um duplo processo em que a afirmação da autonomia é sustentada pela "confiança afetiva na continuidade da dedicação comum" (HONNETH, 2009, p. 178).

Do âmbito do direito, depreendemos o reconhecimento dos sujeitos como pessoas de direito, relacionado à ideia de uma dimensão universal constitutiva das pessoas como tais e que independe de estimá-las por realizações (HONNETH, 2009). Assim, "Honneth se refere não apenas à dimensão legal do reconhecimento jurídico, mas ao pano de fundo moral e normativo anterior à adjudicação de direitos a partir do qual é possível construir o respeito mútuo" (LAGE; CAVALCANTE, 2018, p. 516). Nesse âmbito, a autorrelação prática consigo desenvolvida é a do autorrespeito.

A esfera da estima social refere-se à possibilidade de os sujeitos serem estimados socialmente a partir de suas "propriedades e capacidades concretas" (HONNETH, 2009, p. 198). Considerando um sistema referencial a partir do qual hierarquias valorativas são construídas socialmente, Honneth (2009) afirma que o "valor social" dos indivíduos é medido de acordo com as condições que detêm para contribuir com a sociedade. Dessa forma, "a autocompreensão cultural de uma sociedade predetermina os critérios pelos quais se orienta a estima social das pessoas, já que suas capacidades e realizações são julgadas intersubjetivamente, conforme a medida em que cooperaram na implementação de valores culturalmente definidos" (HONNETH, 2009, p. 200).

Analisar, portanto, as lutas das famílias homoafetivas pela garantia de integridade cidadã, moral e física, sob a luz dessa teoria é um gesto profícuo por se tratar de uma questão de valorização da diferença coletiva que pode ajudar a desvelar a gramática moral do preconceito direcionado a essas famílias.

Na proposta teórica de Honneth (2009), o desenvolvimento bem-sucedido do self, o eu mesmo, é alcançado a partir da garantia do reconhecimento em âmbitos específicos da vida social. Se as formas de reconhecimento forem negadas, experiências de desrespeito são vivenciadas o que gera insatisfações e inquietações e isso pode motivar o sujeito a lutar pelo reconhecimento. Seria esta luta a propulsora de transformações sociais e consequentemente da evolução das sociedades.

O não reconhecimento daqueles três padrões de reconhecimento correspondem três formas de desrespeito: a violação ou violência física, a privação/denegação de direitos e a 
degradação, desvalorização. Tais desrespeitos impedem a autorrealização dos sujeitos e podem suscitar reflexividade e resistência que desencadeiam os conflitos sociais.

Situações de desrespeitos sistemáticas nas diferentes esferas do reconhecimento vivenciadas por sujeitos cujas identidades encontram pontos de convergências com a de coletividades pode levá-los à organização social em busca de garantia de cidadania, igualdade plena, autoconfiança e justiça social, além da interpelação do outro em busca da estima social. Pelo caráter intersubjetivo de sua teoria, Honneth (2013) considera que a formação do sujeito ocorre em meio a grupos sociais nos quais ele vive, por conta da necessidade de serem reconhecidos como membros desses agrupamentos sociais, as quais devem ser atualizadas de modo contínuo. Quando isso não ocorre, "os sujeitos, em especial ali onde o status de sujeito de direito lhes é negado na consciência pública, frequentemente dependem da participação em grupos sociais os quais lhes asseguram uma espécie de respeito compensatório" (HONNETH, 2013, p. 66).

Esses arranjos organizacionais de luta por reconhecimento, que podem ser formais ou informais, representam desafios aos estudos sobre a resistência política de atores cujo as identidades são constantemente subjugadas (SCHERER-WARREN, 2006; MELUCCI, 1989; VIZER, 2007; GOHN, 2011).

\section{MOVIMENTOS SOCIAIS: AÇÃO COLETIVA E LUTA POLÍTICA}

Em um breve balanço sobre as teorias dos movimentos sociais, Alonso (2009) explica que ao longo do século XX as mobilizações coletivas foram ganhando escala global, apontando novos problemas a serem resolvidos, incluindo entre as pautas as lutas identitárias, que reúnem pretensões que ultrapassam as questões de classe, ponto comum nos movimentos tradicionais. Segundo ela, as transformações oriundas das multiplicidades de redes, pautas e atores sociais envolvidos em ações coletivas levaram teóricos a repensar a teoria dos movimentos sociais, pois elas "se constituíram diante de um quadro bastante distinto, o do Ocidente dos anos 1960, quando o próprio termo "movimentos sociais" foi cunhado para designar multidões bradando por mudanças pacíficas (...), desinteressadas do poder do Estado" (ALONSO, 2009, p. 01).

Apesar de não haver um acordo em torno de um conceito entre os teóricos, consideramos neste trabalho que:

O termo movimentos sociais diz respeito aos processos não institucionalizados e aos grupos que os desencadeiam, às lutas políticas, às organizações e discursos dos líderes e seguidores que se formaram com a finalidade de mudar, de modo frequentemente 
radical, a distribuição vigente das recompensas e sanções sociais, as formas de interação individual e os grandes ideais culturais. (ALEXANDER, 1998, p. 01).

Tais movimentos utilizam estratégias específicas de intervenção, como passeatas, paralisações, atos públicos e enfrentamentos, sejam eles discursivos ou corporais. Vizer (2007) explica que os movimentos sociais "representam em princípio a expressão dialética e manifesta da complexidade, a diversidade e a agitação social. Uma forma de ação social que pretende justamente transformar as condições objetivas de seu 'ambiente'” (VIZER, 2007, p. 45). Essas transformações incluem a reconstrução de um sistema de valores e da justiça social. Dessa forma, ele aponta seis características fundamentais de um movimento social:

1. Desenvolver (práticas e dispositivos instrumentais de ação); 2. Com o fim de transformar (as relações e as práticas de poder instituídas (...); 3. Por meio da mobilização (ações de resistência instituintes); 4. Apropriando-se conflitivamente (de tempos e espaços) públicos (cortes de rotas, tomadas de edifícios e empresas fechadas etc.); motivados para cultivar (vínculos, instituições de agrupamento e contenção); 6 . Motivados e inspirados criativamente (o enorme universo da cultura, a comunicação e as formas simbólicas) (VIZER, 2007, p. 46).

De modo complementar, Gohn (2011, p. 335), afirma que os movimentos sociais são "ações sociais coletivas de caráter sociopolítico e cultural que viabilizam formas distintas de a população se organizar e expressar suas demandas". Os sujeitos reunidos em movimentos, diz Gohn (2011), estão organizados em prol da ação e tais atividades proporcionam inovações socioculturais: "os movimentos são o coração, o pulsar da sociedade. Eles expressam energias de resistência ao velho que oprime ou de construção do novo que liberte" (GOHN, 2011, p. 336). São os movimentos, segundo a autora, os responsáveis pela construção de propostas e alternativas aos problemas sociais identificados a partir de diagnósticos prévios e demandas coletivas apresentadas na esfera pública ${ }^{3}$.

A teoria do reconhecimento apresenta novos diálogos à teoria dos movimentos sociais, conforme pontua Garcêz (2014), pois propõe uma teoria da justiça centrada nos conflitos sociais, assim como para o estudo dos movimentos sociais, o conflito e a identidade também são elementos centrais para a teoria do reconhecimento. Ao estabelecerem ações coletivas, os sujeitos saem de uma posição de rebaixamento para se apresentarem como agentes de transformação.

\footnotetext{
${ }^{3}$ Entendemos esfera pública a partir da concepção habermasiana segundo o qual trata-se de uma dimensão comunicativa em que são debatidos temas concernentes aos cidadãos conformando uma esfera de discussão que ocorre em diversos ambientes, formais ou informais. É por meio da esfera pública e do processo de construção das opiniões públicas que ocorrem processos mediadores entre o Estado e a sociedade, pois seria essa a dimensão capaz de efetivar a participação dos sujeitos em processos democráticos (HABERMAS, 2003).
} 
Mas, para posicionar a teoria do reconhecimento como uma das contribuições possíveis às teorias dos movimentos sociais, e não especificamente mais uma teoria dos movimentos sociais, Garcêz (2014) desenvolve algumas ressalvas: 01) conflito: o conflito perpassa todos os âmbitos do reconhecimento, e podem vir a se tornar uma ação coletiva por meio de lutas sociais organizadas, portanto, nem toda demanda por reconhecimento torna-se movimento social. " $\mathrm{O}$ conflito não ganha necessariamente conotação de uma ação coletiva estruturada, mas de uma relação intersubjetiva conflituosa com potencial normativo" (GARCÊZ, 2014, p. 05); 02) nem todo conflito gera luta por reconhecimento, mas apenas aqueles capazes de sacudir os padrões normativos e provocar tensão moral, superando, assim, pretensões individuais; 03) as lutas por reconhecimento são constituídas para além dos conflitos oriundos das diferenciações identitárias coletivas e, também, da valorização cultural. Relegá-la a esse papel é esvaziar o conceito de reconhecimento e permitir interpretações equivocadas como as demandas de grupos intolerantes, por exemplo.

\section{PROCEDIMENTOS METODOLÓGICOS}

Nosso objetivo geral neste trabalho é compreender como são mobilizadas as dimensões do afeto e da solidariedade na luta política da estrutura organizacional da Abrafh. Especificamente queremos: a) investigar a relação entre a luta política e o estabelecimento de redes de afeto e solidariedade em ação coletiva; b) Compreender quais são as estratégias de intervenção na agenda social e como interagem com os anseios de quem compõe a luta; b) Identificar quais elementos são utilizados pela instituição, por meio de seus diretores, para reunir os sujeitos e estabelecer redes de apoio, solidariedade e afeto.

Para isso, realizamos entrevista semiestruturadas com quatro diretores da associação. A interlocução com os sujeitos da pesquisa foi mediada por um roteiro norteador. Composto de onze perguntas, o roteiro permitiu levantar informações sobre como surgiu a Abrafh; quais as principais pautas de luta política da instituição; entender como a diretoria percebe, e se há, a resistência da sociedade em relação às pautas defendidas; como a Abrafh atua para enfrentar o preconceito e a agenda conservadora de segmentos da sociedade; quais as maiores dificuldades e desafios na gestão desse movimento e dessas pautas.

Da leitura e da transcrição das entrevistas, a partir da perspectiva do referencial teórico do reconhecimento, emergiram três categorias de análise que nos permitiram observar a partir de cada uma das esferas do reconhecimento (amor, direito e estima social) como é desenvolvida a luta social na Abrafh e o esforço para estabelecer vínculos e redes socioafetivas entre os 
sujeitos que compõem a associação. As categorias foram: 01) no âmbito do amor fortalecimento de laços entre iguais; 02) no âmbito do direito - apoio jurídico na esfera institucional; 03) no âmbito da estima social - agenda de ações pautadas na representatividade positiva das famílias. A partir da elaboração das categorias analíticas, realizamos a análise qualitativa de conteúdo discursivo, conforme proposto por Mendonça (2009) que descreve pelo menos três passos fundamentais para esse procedimento: descrição inicial, codificação das dimensões do reconhecimento e cruzamento dos âmbitos.

Observamos nas falas dos entrevistados: 01) como se referem à Abrafh (definições, conceitos e formas de referir-se a ela); 02) como são definidas as principais linhas de atuação; 03) como as estratégias são colocadas em práticas e quais são; 04) quais as conquistas práticas a diretoria aponta como sendo oriundas da atuação institucional. A partir desse olhar, procuramos nos argumentos a relação entre a luta empreendida pela associação, segundo a diretoria, e o elaboração de estratégias para o estabelecimento de relações e vínculos de afetos; observamos nos dados encontrados como eles dialogavam com cada âmbito do reconhecimento.

\section{RESULTADOS E DISCUSSÃO}

A entrevista nos forneceu elementos para entender como a diretoria concebe o ideal que impulsiona a Abrafh. Por ser a primeira diretoria oficial e por ser formada por membros fundadores, foi possível acessarmos nas entrevistas os motivos da criação da instituição, os pilares fundamentais que originaram os objetivos, a missão e a visão da atuação da entidade, assim como os objetos da causa, as propostas, estratégias e ações que nos mostraram como a Abrafh propõe-se a representar as famílias homoafetivas.

\subsection{NO ÂMBITO DO AMOR - FORTALECIMENTO DE LAÇOS ENTRE IGUAIS}

Ao ampliar a noção de família para um contexto associativista, a Abrafh se propõe a dedicar parte do trabalho que desenvolve ao exercício de estabelecer laços afetivos entre as famílias associadas. Parte da agenda da instituição inclui passeios, piqueniques, encontros e reuniões realizadas em ambientes propícios ao estabelecimento de convívio social, ao diálogo e às trocas afetivas entre as famílias, com especial atenção àquelas que possuem filhos. Esse aspecto aparece na fala do então presidente, ao apontar quais estratégias são desenvolvidas pela Abrafh para proporcionar autoconfiança aos sujeitos: 
Presidente: $\mathrm{Na}$ questão psicossocial criamos um grupo de apoio, que tem dois caminhos: um de apoio às pessoas LGBTI para se aceitarem, para discutirem as suas situações, e outras em relação aos pais e parentes de pessoas LGBTI que sentem a dificuldade para consolidar sua vida e sua relação com seus entes queridos. Em relação a isso, até interessante registrar que a Abrafh tem cada vez mais sendo procurado por familias ditas heterossexuais, heteronormativas, porque descobrem que seus filhos são lésbicas, ou gays, ou trans ou bissexuais, e não sabem como lidar pela ausência de um modelo (Meio eletrônico, 2017, grifo nosso).

A entidade propõe ações práticas que buscam suscitar o sentimento de pertença, além de contribuir com o processo de estabelecimento da autoconfiança advindo da autorrelação prática no âmbito do amor. A Abrafh atua, de acordo com as falas dos entrevistados, para evitar as formas de desrespeito. Segundo Honneth (2009), no âmbito do amor, os desrespeitos ocasionam os maus-tratos e a violação, nas quais o componente ameaçado da personalidade é, sobretudo, a integridade física. Para Honneth (2009), o indivíduo se constitui como sujeito a partir da perspectiva do outro em um movimento intersubjetivo de construção das identidades. $\mathrm{O}$ autor afirma que a autoconsciência depende do encorajamento ou assentimento do outro. É por meio da intersubjetividade que cada um aprende a referir-se a si mesmo e a reconhecer capacidades e propriedades que o constituem. Ao dispensar esforços para propor o estreitamento de relações entre as famílias, a Abrafh atua especificamente sobre a dimensão afetiva das relações intersubjetivas:

Vice-presidente: Falar de familias é diferente de levantar bandeiras em paradas. Não fazemos a militância tradicional. Temos também como meta unir as famílias, promover encontros para que se sintam inseridos num contexto maior e sobretudo para que as crianças se sintam mais integradas, convivendo com famílias semelhantes (Meio eletrônico, 2017, grifo nosso).

A forma como a vice-presidente se refere à militância da Abrafh define o modo como a diretoria entende a própria atuação política, e como se distinguem de outras formas lutas tradicionais. Ela insere a família em uma categoria que exigiria outras ferramentas de luta que não as usuais. Nessas ferramentas, o afeto se constitui como eixo norteador. A aproximação das famílias, a nosso ver, é uma tentativa de fomentar laços afetivos e, nos termos de Honneth, uma forma de construção de "pontes simbólicas" entre os sujeitos, motivados a alcançarem mutuamente formas de confiança em si mesmos e na manifestação de suas carências e inseguranças afetivas. Nesse sentido, a Abrafh se coloca como extensão dos laços afetivos que os núcleos familiares nutrem entre si, criando um senso de pertencimento e, principalmente, de dedicação mútua: 
Diretor de comunicação: um dos grandes ideais da Abrafh é que a gente busca criar essa rede de contatos entre os membros, não só de poder ter um ambiente onde as pessoas possam se conhecer, possam dar como oportunidade a seus filhos se relacionarem com outros pais que também sejam homoafetivos. Tanto é que esse é um dos grandes impasses que os pais dizem que as crianças sentem. Apesar de eu não ser pai, eu ouço bastante o que o pessoal comenta. As crianças falam: "Ah, mas eu não conheço nenhum outro filho de casal que tenha papais de mesmo sexo". Então esse ambiente mais familiar, mais harmonioso, que a Abrafh também está propiciando através dos piqueniques, dos encontros, diretamente ele não tem nenhuma ação política, mas indiretamente ele tem, sim, como atitude uma política, porque ele $f a z$ com que as pessoas criem laços de afetividade, se unam, se engajem, e, a partir disso, possam fomentar lutas dentro de suas próprias localidades (Meio eletrônico, 2017, grifo nosso).

Diretor de Relações Institucionais: A Abrafh não é clube, a Abrafh não é ONG, a Abrafh não é entidade de classe, ela não é entidade filantrópica. Então não é uma entidade que vai se preocupar em promover serviços, em entregar serviços aos seus membros, isso é um clube, é uma ONG, né. A Abrafh vai se preocupar em representar os seus membros e identificar as necessidades, carências, dos seus membros, e ser uma pessoa jurídica que fale por eles e que vá, em nome deles, ao encontro das suas necessidades, em âmbito nacional, regional, estadual, municipal. (...) a gente vai alcançar o objetivo de ser uma associação quando nós conseguirmos aproximar pessoas. (...) Então a gente precisa realizar eventos, precisa sensibilizar e motivar as pessoas para se encontrarem pessoalmente, para se conhecerem, para trocarem experiências de vida, para discordarem, concordarem, dialogarem sobre as necessidades próprias suas, enquanto pessoas, e suas famílias (Meio eletrônico, 2017, grifo nosso).

É na "força emancipatória da interação que Honneth deposita suas esperanças de um mundo melhor" (MENDONÇA, 2009, p. 145). À luz dessa perspectiva, percebe-se que os esforços da Abrafh, tal como indicados pelos seus idealizadores, buscam não apenas um alinhamento discursivo na instauração de um posicionamento político, mas, sobretudo, uma oportunidade de estabelecimento de relações de amizade, solidariedade, empatia e confiança mútua, capazes de influir sobre a própria capacidade dos sujeitos para estabelecer uma confiança na possibilidade de satisfazerem socialmente suas demandas e necessidades afetivas.

Verificamos a existência de um discurso que nega a atuação da Abrafh como uma ação coletiva clássica, cujo interesse, também, estaria centrado na disputa de espaços de poder, no sentido de garantir representatividade em ambientes legalmente constituídos e inserção representativa em movimentos identitários mais amplos que, de certa forma, exigem embates mais diretos e incisivos. Ou seja, havia entre os entrevistados da diretoria quem apontasse as ações da Abrafh como uma nova forma de fazer política, desta vez centrada no afeto e na fuga ao enfrentamento:

Vice-presidente: vejo a Abrafh como a união de várias famílias que só querem viver em paz com seus amores e seus filhos, sem precisar ir para a rua, se arriscarem ante a selvageria que atinge os ativistas clássicos (Meio eletrônico, 2017). 
Observamos que a dimensão afetiva é crucial para o trabalho da entidade. O que nos parece elemento definidor de uma forma de ação política em busca do reconhecimento, pois remete a uma das esferas vezes negligenciada nos debates sobre movimentos sociais e conflitos. As tensões sobre a forma como cada diretor entende a concepção da Abrafh surgem neste momento dos diálogos que travamos com eles, o que encaramos como um processo natural que envolve o associativismo, ambiente no qual a igualdade é trabalhada de forma nãohomogeneizadora.

Se de um lado há quem negue a atuação representativa junto aos movimentos sociais clássicos, com ações coletivas de manifestação, piquetes, passeatas e demais, há também quem tenha apontado o surgimento da Abrafh como resultado da discordância quanto às formas de atuação política. As estratégias dialogam com o que Vizer (2007) aponta como sendo características de movimentos sociais, que são o desenvolvimento de práticas e instrumentos de ação, mobilização, composição de espaços como entidade representativa de dada temática e motivando e inspirando os integrantes do movimento. O descontentamento com os movimentos tradicionais, que aparece na fala transcrita abaixo, aponta para a forma como a Abrafh foi fundada:

Diretor de comunicação: então, talvez a Abrafh tenha surgido justamente nessa mistura de angústia e de rebeldia, de lutar, de contra-atacar, de mostrar que não é assim. Então a Abrafh praticamente surgiu nesse ambiente totalmente hostil, agressivo, totalmente inóspito a um diálogo profícuo, a um diálogo respeitoso e democrático, e ela veio justamente dessa necessidade (Meio eletrônico, 2017).

Ainda que esteja em constante tensionamento com setores conservadores da sociedade, os diretores acreditam ser necessário evitar embates simbolicamente violentos e cujo os discursos possam ser mal interpretados ou que venham servir de munição para que as famílias sejam atacadas. Assim, na esfera do amor, as definições da Abrafh são caracterizadas por uma instituição que se propõe a proteger as famílias, também, dos ataques oriundos de debates violentos que possam ocorrer no cerne da luta política. Ao se apresentarem como agentes de transformação que evitam o ataque direto aos detratores, a direção da Abrafh se define como uma organização que fala de famílias para famílias e direcionam os esforços no sentido de construir a autonomia dos sujeitos sem que para isso pratiquem ações coercitivas e/ou de enfrentamento direto com outros sujeitos, sobretudo com aqueles que atuam em uma direção contrária.

\subsection{NO ÂMBITO DO DIREITO - APOIO JURÍDICO NA ESFERA INSTITUCIONAL}


Observamos nas falas dos diretores entrevistados que as definições sobre a Abrafh, assim como as ações práticas empreendidas pelos participantes, estão voltadas em grande parte para questões legais, relacionadas ao reconhecimento dos sujeitos como pessoas autônomas, à concretização de direitos e à efetivação da cidadania:

Diretor de Relações Institucionais: então se sentiu justamente a necessidade de ter uma entidade que se preocupasse com essas questões familiares, questões de registros, questão de casamento civil, paternidade, adoção, divórcio, sucessão, representação familiar, a questão legal mesmo, o quanto que a gente tem ainda de carência de dispositivos legais que deem amparo à existência das nossas famílias (Meio eletrônico, 2017, grifo nosso).

Presidente: é fundamental que haja a equiparação dos direitos, por vias legais, como a criminalização da LGBTfobia. Do respeito através de alguns pontos cruciais, como casamento igualitário, como impedimento de qualquer restrição à cidadania. E a partir daí, juntar o empoderamento das pessoas, tanto na via psicológica, jurídica, social, econômica, profissional, com a vida comum. Levar, mostrar, que todos podemos e devemos ter uma vida comum, sem qualquer receio (Meio eletrônico, 2017, grifo nosso).

A preocupação com os direitos sociais das famílias homoafetivas foi o principal pilar da criação da Abrafh. É no campo dos direitos, disseram os entrevistados, que circulam as ações práticas que elevaram a instituição ao status de representação das famílias homoafetivas, e isso inclui a participação nos media e em espaços de diálogo político e interinstitucional. Ao fazermos referência ao direito como âmbito da luta por reconhecimento, trazemos à tona as relações intersubjetivas enquanto fenômenos regulados por princípios morais universalistas pautados na imputabilidade dos sujeitos, que, ao reconhecerem os outros como dotados de direitos, reconhecem-se como igualmente detentores de direitos.

Honneth (2009) afirma que as relações intersubjetivas no campo do direito ultrapassam o estado de dependência afetiva da primeira forma de reconhecimento. Para garantir a liberdade individual, o sujeito precisa reconhecer que os parceiros de interação também são livres e igualmente autônomos. A conquista da autorrelação prática nesse âmbito gera o autorrespeito. Essa busca por autonomia aparece em algumas falas:

Diretor de Relações Institucionais: quando aparece uma oportunidade, nós somos procurados ou nós descobrimos como oportunidade, nós nos movimentamos para ir ao encontro. Assim foi com a questão da doação de sangue ${ }^{4}$, que nós entramos como amicus curiae juntos no processo que tramita no Supremo Tribunal; algumas manifestações públicas, recentemente apoio ao Ministério Público para a questão dos registros das pessoas trans, para facilitar a questão do registro, para não ter que recorrer ao Judiciário, para poder mudar as certidões, os documentos, essas coisas assim (Meio eletrônico, 2017, grifo nosso).

\footnotetext{
${ }^{4}$ No Brasil, duas normas, uma da Anvisa (Agência Nacional de Vigilância Sanitária) e outra do Ministério da Saúde, proíbem homens que tenham feito sexo com outros homens de doarem sangue nos 12 meses subsequentes ao ato.
} 
Consolidar os direitos das famílias cujo núcleo é formado por pessoas homossexuais é um dos objetivos da instituição. Para que isso ocorra, a diretoria entendeu ser necessário trabalhar em rede. Nesse sentido, a Abrafh articulou, junto aos membros que atuam nas mais diversas esferas da sociedade, a formação de uma rede de atores sociais com algum grau de representatividade junto ao poder público e ao terceiro setor, de maneira que a associação tivesse entrada e pudesse atuar em parceria frente às ações práticas de garantia dos direitos individuais e coletivos. Ações em redes ocorrem quando movimentos organizados em torno de uma mesma temática agem de forma conjunta e articulada. No caso da Abrafh e seus parceiros, como o Instituto Brasileiro de Direito de Família (IBDFAM), entidade vinculada à área de Direito de Família, a temática que os une são, também, os direitos das populações LGBTQI+. A inserção da Abrafh na agenda de lutas é refletida na procura da instituição por outras entidades com objetivo de consulta ou estabelecimento de parcerias, como vislumbramos no relato abaixo:

Presidente: além das questões das campanhas, das questões de visibilidade, a gente tem, entre os nossos membros, ações pontuais, legislativas. Nós temos ligações com alguns deputados federais, alguns senadores que apoiam a nossa causa. A nossa parceria com o IBDFAM no fechamento do estatuto das famílias, no estatuto da diversidade, os dois projetos que estão no Senado Federal. E também nas questões jurídicas, a gente tem sido bastante procurado por alguns juízes, e até desembargadores, antes de proferir suas decisões, tentando embasar entendimento com informações que, infelizmente, eles não têm, mas que pelo menos estão procurando ler para consolidar com decisões a nosso respeito, né? (Meio eletrônico, 2017, grifo nosso).

Ao nos referirmos ao autorrespeito como um dos padrões intersubjetivos de reconhecimento, o que está em jogo é a própria possibilidade de a pessoa ver a si mesma como deliberadora competente e como coautora legítima de decisões tomadas no plano das ações. Nesse sentido, um sujeito cuja experiência seja marcada pela subordinação, pela exclusão ou mesmo pela negligência de seus direitos tem ameaçada sua própria capacidade de se levar a sério em seu próprio raciocínio prático sobre o que fazer e como agir. É quando sofre violação desses direitos que o sujeito sofre com o rebaixamento moral e isso afeta o autorrespeito (HONNETH, 2009). A fala abaixo aponta para esse sentimento de exclusão, motivado pelos avanços ainda insuficientes e intermitentes na esfera do Direito:

Diretor de Relações Institucionais: a gente sabe que a maioria dos ganhos, dos poucos, que a gente tem, são oriundos do Poder Judiciário, são decisões que de uma hora para outra, uma mudança normativa legal pode inviabilizar esses ganhos que a gente já tem no Judiciário, enfim. Percebendo essa carência de uma entidade que se preocupasse especificamente com famílias, se deu esse pontapé inicial que fez a Abrafh surgir (Meio eletrônico, 2017, grifo nosso).

LOGEION: Filosofia da informação, Rio de Janeiro, v. 6 n. 1, p.85-105, set.2019/fev. 2020 
A despeito das conquistas legais efetivas na esfera jurídica, importa para Honneth (2009), sobretudo, os esquemas morais que constituem as bases para a possibilidade ou impossibilidade de reconhecimento recíproco da imputabilidade moral de todos os membros da comunidade jurídica. Basicamente, o filósofo chama atenção para o fato de que a assunção da igualdade de direitos expressa interesses universalizáveis de todos os membros da comunidade, pressupondo a recusa a lógicas excludentes e de privilégios. Nesse sentido, surgem questões ligadas às experiências cotidianas de desrespeito à igualdade de direitos desses sujeitos. $\mathrm{O}$ presidente da entidade aponta para questões práticas da vida de um casal homoafetivo, tais como o casamento civil, a herança, a adoção, o sistema cartorário de documentações, entre outros aspectos da vida burocrática. Nessa mesma linha de entendimento está a fala do diretor de comunicação, que explica ter conhecido a proposta da Abrafh justamente em virtude dessa questão.

Presidente: a gente conversou bastante e definimos que a linha também teria que ser na luta pelos direitos, não só dessas crianças, mas de toda e qualquer composição familiar. Na luta pelos direitos que vinham sendo estabelecidos pelo poder judiciário e não pelo legislativo, através de decisões, mas não através de leis ou de emenda constitucional, o que fica de certa forma em uma situação muito delicada, passível de uma mudança, de um retrocesso. Então, definimos que as questões legais estariam inseridas nos objetivos iniciais da associação (Meio eletrônico, 2017, grifo nosso).

Diretor de comunicação: quando você vai registrar o seu filho, seja na Receita Federal, seja na Justiça Eleitoral, os dois sistemas dão uma espécie de erro, porque um considera no campo mãe o outro pai, e no outro não considera nenhum membro que não seja a mãe no campo mãe. A mãe fica ausente. Daí, na hora que os dois sistemas vão se comunicar, dá erro e você não consegue nem gerar o título de eleitor e nem cadastrar o filho na Receita Federal. Então o conselho jurídico já está fazendo um estudo de caso para ver como elencar isso para o TSE, ou mesmo para a cúpula da Receita Federal, para ver como resolver essa questão, que é uma questão que está sendo vista só agora, porque não é tão recente assim que os casais homoafetivos masculinos tenham filhos acima de 16 anos. (Meio eletrônico, 2017, grifo nosso).

A Abrafh recebe inúmeros questionamentos de casais homossexuais que querem adotar, ou que querem se casar, ou que simplesmente querem entender se de fato constituem uma família e o que devem fazer para que isso seja considerado perante o Estado democrático brasileiro. Nesse sentido, a entidade concentra parte de sua atuação política na própria luta pela garantia de direitos. Entretanto, a dimensão da esfera jurídica está além da consultoria para assuntos referentes aos direitos legalmente estabelecidos. Trata-se de um esforço no sentido de garantir amparo legal para demandas que não são exclusivas de uma família, mas de todas. Ou seja, não está em jogo apenas a garantia de direitos, mas sobretudo o reconhecimento de que tais famílias têm direito a ter direitos, e que elas podem encontrar nesse grupo o amparo comunitário e a devida ajuda para buscar sua realização no que diz respeito à vida familiar: como casar e criar filhos, por exemplo. 


\subsection{NO ÂMBITO DA ESTIMA SOCIAL - AGENDA DE AÇÕES PAUTADAS NA REPRESENTATIVIDADE POSITIVA DAS FAMÍLIAS}

Entendemos que as ações voltadas para autorrealização no âmbito da solidariedade empreendidas pela Abrafh se dão na perspectiva Abrafh X sociedade (ou sociedades) brasileira. Ou seja, categorizamos aqui expressões encontradas nas falas dos entrevistados que revelam aspectos da atuação institucional que buscam o respeito e também a afeição dada ao sujeito pelo grupo social amplo, com aqueles que são "diferentes" e, logo, não compartilham do mesmo estilo de vida - sexualidades e identidades de gênero diferente das consideradas padrões. Nas expressões, encontramos um dialogismo entre famílias homoafetivas X sociedade patriarcal conservadora que revela certa tensão.

Para serem reconhecidas como famílias por outros membros da sociedade, as famílias homoafetivas reunidas na Abrafh desenvolvem ações baseadas no que eles convencionaram chamar de visibilidade positiva. O presidente explicou do que se trata:

Presidente: nós chamamos de campanha de visibilidade positiva, para mostrar à sociedade que toda e qualquer família merece respeito e tem que ser considerada como comum para toda a sociedade. (...) em que a gente mostra a cara, discuta, mostra para a sociedade que a gente tem que ter o respeito, tem que ter a consideração, e aí é um estímulo que a gente faz não só à participação de todos os nossos membros de suas famílias, como de outras famílias, para que saiam efetivamente do armário, não é mais o gay, a lésbica, a trans saindo do armário, mas as famílias saindo do armário e mostrando a cara à sociedade (Meio eletrônico, 2017, grifos nossos).

Essa sensação de ser querido, respeitado, pode proporcionar um estado de aceitação das diferenças que lhes são inerentes (habilidades, características peculiares e até as escolhas individuais) e que influencia diretamente na autoestima do sujeito. Para Honneth (2009), além do caráter do reconhecimento mútuo das capacidades individuais, essa categoria reúne também um componente emocional, pois estamos lidando também com a empatia. Como um dos âmbitos do processo de autorrealização, a estima social possui uma relação próxima com o papel que o sujeito desempenha na sociedade, ou seja, quais as capacidades de contribuição do sujeito para o bem-estar social e isso inclui, também, o mundo do trabalho.

Para os diretores, a troca de afeto em público, por exemplo, é uma forma de se fazer presente, marcar espaço enquanto entidade familiar dotada do mesmo direito que todos. Mostrar-se enquanto sujeito digno de afeição, segundo a fala do presidente, é uma forma de resistência e de encorajamento. Quando ele se refere à informação como elemento importante na transformação social, com vistas à diminuição da discriminação e do preconceito está reivindicando uma transformação de padrões morais sobre o que é ser uma família. Segundo 
Narvaz e Koller (2006), a sobrevivência e a perpetuação da espécie levaram o homem a diferentes formas de se relacionar com a natureza e entre eles mesmos e dessa forma surgiram as diversas formas de organizações familiares e parentescos.

A invenção das famílias cumpre ritos oriundos de determinada cultura inserida em certa temporalidade. Portanto, se há um movimento de transformação social oriundos da fragmentação subjetiva dos sujeitos podemos afirmar que há, também, campo propício para ampliação das relações afetivas em núcleos familiares. Essa publicização dos afetos requeridas pela Abrafh contribui com a inserção de tais práticas no universo social. Rompendo, então, com o padrão heterossexual da relação familiar.

Ao fortalecer a visibilidade positiva, a diretoria entende que estará contribuindo para o processo de aceitação e valorização das famílias homoafetivas junto à sociedade:

Presidente: É fazer chegar ao público, por entrevistas, artigos, documentários, narrativas, histórias de famílias homoafetivas comuns onde o afeto prevalece, é contar histórias reais, que são um contraponto às manchetes policiais, em que LGBTs são vítimas ou protagonistas de casos de violência. Contamos casos de adoção, de maternidade e paternidade homo e transafetiva que deram certo e, assim, passamos imagem positiva, promovemos a visibilidade positiva (Meio eletrônico, 2017, grifos nossos).

De acordo com as expressões aqui coletadas, a Abrafh tem atuado de forma sistemática nessa questão e tem se apresentado como uma organização que pode congregar as mais diferentes famílias e, assim, se apresentarem à sociedade como modalidades tão legítimas quanto a família nuclear. Essa luta ocorre em direção à estima social e a partir de estratégias de visibilidade das famílias nos mais diferentes ambientes. É por meio das relações de solidariedade conformada por uma nova gramática sobre o que é ser família que a Abrafh espera garantir relações de respeito. É nesse ponto que observamos os aspectos da luta da Abrafh que nos fazem identificá-la como um movimento social organizado, já que luta para inserir as temáticas das famílias homoafetivas no horizonte de valores por meio do debate na esfera pública e da apresentação de suas pautas em ambientes deliberativos:

Ao reivindicar a igualdade de acesso a direitos, a Abrafh está afirmando que nem todos são iguais perante à justiça e seria para garantir essa igualdade que a instituição foi criada. Assim, os membros teriam onde encontrar amparo tanto afetivo quanto colaborativo, visto que a entidade possui uma rede de suporte jurídico para auxiliar os filiados em ações e com informações sobre outros casos que possam servir como base e até jurisprudência. E isso se confirma na fala da vice-presidente:

Vice-presidente: o apoio psicológico e aconselhamento jurídico também são importantes ferramentas para promover a cidadania e os direitos de nossas famílias. 
O Ministério Público, a Defensoria Pública, a OAB e suas regionais e Comissões de Diversidade Sexual têm sido importantes parceiros em ações pontuais e no direcionamento dos casos (Meio eletrônico, 2017, grifo nosso).

A parceria com diferentes agentes, tanto públicos quanto da esfera privada, como escritórios de advocacia, surge como uma expressão de orgulho nas falas dos entrevistados. Para eles, o estabelecimento dessas parcerias aponta para uma "boa-vontade" de muitas organizações em abraçar a causa das famílias homoafetivas. Uma questão específica sobre a forma de militância da Abrafh nos chama atenção. Para a diretoria, a associação é diferente porque não desenvolve o ativismo cotidiano clássico, denominado pelo diretor de comunicação como um "ativismo combativo", e de certa forma "agressivo". Na visão dele, a Abrafh quer um ativismo mais suave, positivo, "abarcadora".

Essa noção de ativismo apresentada pelos entrevistados toma como estratégia tradicional dos movimentos sociais o enfrentamento radical, por meio de atos, greves e manifestações. Contudo, trata-se de uma noção notadamente enviesada e enquadrada em clichês. É preciso levar em consideração que os movimentos sociais contemporâneos são formados por grupos identitários reconhecidos como minorias políticas que são constantemente subjugados e relegados às margens das instâncias de tomadas de decisão. Por isso, em muitos casos, é necessário lutar de forma mais contundente.

Assim, temos uma associação que se define como entidade da sociedade civil organizada que busca na união das famílias homoafetivas uma forma de se apresentarem aos demais seguimentos sociais como capazes e autônomas. Segundo Honneth (2009), o âmbito da estima social diz respeito à vida em comunidade e aos valores do sujeito que ao ter reconhecimento negado nesse âmbito vivencia a degradação e ofensa que são categorias de rebaixamento relacionadas à depreciação do estilo de vida individual ou grupal. Nos relatos estudados, percebemos que a Abrafh tem atuado no sentido de proteger seus associados de tais formas de depreciação.

\section{CONSIDERAÇÕES FINAIS}

A Abrafh, em sua proposta, define-se como iniciativa de acolhimento, defesa e representação das famílias homoafetivas, no sentido de tornar os indivíduos atravessados pelo marcador da homotransafetividade cidadãos capazes de estabelecer confiança em si mesmos e nos próprios sentimentos, desejos, impulsos, emoções... Isso porque, uma vez agredidos ou cerceados, os sujeitos passam a ver seus próprios sentimentos com desconfiança. E aqueles que 
perderam essa confiança perderam a base para conduzir suas vidas de acordo com suas convicções mais básicas. São famílias formadas por LGBTQIA+ que têm ou pretendem ter filhos, apesar de a diretoria afirmar que casais sem filhos também compõem o corpo de filiados e são consideradas famílias homoafetivas. Assim, a partir das entrevistas, percebemos que os principais eixos estratégicos da atuação política e institucional da Abrafh são: o congraçamento entre sujeitos e famílias por meio de atividades cívicas coletivas; o voluntariado; o apoio psicossocial; o suporte jurídico; o posicionamento público da instituição; a participação em eventos e campanhas de visibilidade; as reflexões acadêmicas e o posicionamento institucional perante o estado.

O exame dos discursos produzidos pela diretoria da Abrafh é revelador de que o que está em jogo, na atuação política da entidade, é principalmente a possibilidade de responder satisfatoriamente à necessidade que os sujeitos têm de desenvolverem conexões baseadas na confiança afetiva na continuidade da dedicação mútua. É apenas dessa forma que eles podem afirmar sua autonomia de par com sua autoconfiança. Nesse sentido, e a despeito do particularismo moral que atravessa o amor, tal sentimento é pré-condição para o desenvolvimento da autoconfiança, que, por sua vez, é elementar para o engajamento social dos sujeitos. Ao investir sobre a possibilidade de construção de relações de afeto, amizade e interesse mútuo, a associação se mostra atuante politicamente em uma esfera muito específica da luta por reconhecimento: o amor, tomado aqui como fundamento intersubjetivo do estabelecimento da confiança, por parte dos sujeitos, nas próprias necessidades de afeto e na própria possibilidade de recebê-lo por parte de outros indivíduos.

Assim, se vemos, em geral, entidades cuja atuação política está concentrada quase que exclusivamente na revisão dos esquemas morais que distribuem a estima social e nas possibilidades do exercício dos direitos, o discurso dos diretores da Abrafh é revelador de uma atuação direcionada a outras demandas, igualmente importantes para a possibilidade de construção de formas de autorrelação prática que levem à autorrealização dos sujeitos. Como fica claro nas entrevistas que nos foram concedidas, as experiências que motivaram a criação da Abrafh também são pautadas nos desrespeitos, sobretudo aqueles sofridos no âmbito jurídico-institucional, mas não sem considerar as formas de maus-tratos e violações pelas quais passam cotidianamente quem ousa "tirar sua família do armário" e recebe do outro, os interlocutores, o preconceito e a exclusão.

Ao fazermos referência ao amor e ao afeto como âmbitos da atuação política da entidade, projetamos ao menos dois conjuntos de problemas: em primeiro lugar, o da autoconfiança como tipo de autorrelação prática construída a partir da possibilidade de os 
sujeitos se verem ao olhos dos outros como seres dignos de dedicação afetiva; em segundo lugar, o da construção de um senso de coletividade no qual os sujeitos encontram a possibilidade de serem valorizados afetivamente, respeitados em sua capacidade de julgar e de agir conforme as normas, características e habilidades pessoais. Conforme argumenta Honneth (2013), grupos sociais asseguram aos indivíduos um respeito compensatório, especialmente em condições nas quais o status de sujeito lhes é negado. Nesse sentido, a solidariedade integra essa atividade política não apenas no sentido da busca pela estima social em oposição às formas de humilhação, mas, sobretudo, a solidariedade como forma de construção de relações interpessoais baseadas nas trocas afetivas, no apoio mútuo, no convívio, na amizade e na confiança.

É possível observar que o leque de atuação é grande e que, ao atuar no campo das famílias, a instituição entende que há uma série de ações que podem ser caracterizadas como pertencentes aos limites do debate sobre a entidade familiar, desde a proteção dos filhos, passando pelo direito ao casamento até o combate à homofobia e a capacitação de membros das famílias para que se apropriem de conhecimento e adquiram autonomia, inclusive financeira. Portanto, como podemos observar, há na Abrafh um senso de luta por justiça que passa, antes de qualquer outra forma de engajamento, pelo encorajamento à construção de laços afetivos entre sujeitos unidos em torno de um sentido de comunidade. 


\section{REFERENCIAS}

ALEXANDER, Jeffrey. Ação Coletiva, Cultura e Sociedade Civil: Secularização, atualização, inversão, revisão e deslocamento do modelo clássico dos movimentos sociais. Rev. bras. Ci. Soc., São Paulo, v. 13, n. 37, p. 5-31, Jun, 1998. Disponível em: http://www.scielo.br/scielo.php?script=sci_arttext\&pid=S0102$69091998000200001 \& \operatorname{lng}=\mathrm{en} \& \mathrm{nrm}=$ iso . $\overline{\text { Acesso em: }} 30$ nov. 2017.

ALONSO, Angela. As teorias de movimentos sociais: Um balanço do debate. Lua Nova, $\mathrm{n}$. 76, São Paulo, CEDEC, p. 49-86, 2009. Disponível em:

http://www.scielo.br/pdf/ln/n76/n76a03 . Acesso em: 20 set. 2017.

GARCÊZ, Regiane Lucas de Oliveira. Teoria do Reconhecimento: uma teoria dos movimentos sociais? In: SIMPÓSIO NACIONAL SOBRE DEMOCRACIA E DESIGUALDADES, 2, 2014, Brasília. Anais... Brasília: Universidade de Brasília, 2014.

GOHN, Maria da Glória. Movimentos sociais na contemporaneidade. Revista Brasileira de Educação, v. 16, n. 47, mai./ago., 2011. Disponível em:

$<$ http://www.scielo.br/pdf/rbedu/v16n47/v16n47a05.pdf > Acesso em: 13 set 2019.

HABERMAS, Jürgen. O papel da sociedade civil e da esfera pública política. In: Direito e Democracia: entre facticidade e validade. Volume II. Rio de Janeiro: Tempo Brasileiro, 2003. p. 57-123.

HONNETH, Axel. Luta por reconhecimento: a gramática moral dos conflitos sociais. 2. ed. São Paulo: Editora 34, 2009.

HONNETH, Axel. O eu no nós: reconhecimento como força motriz de grupos. Sociologias, v. 15, n. 33, 2013.

LAGE, Leandro; CAVALCANTE, Tainá. ESTIMA SOCIAL E LINGUAGENS DA SOLIDARIEDADE: pessoas com Síndrome de Down e a luta por reconhecimento. Revista Observatório, v. 4, n. 6, p. 506-543, 8 out. 2018.

MELLUCI, Alberto. Um objetivo para os movimentos sociais? Lua Nova, São Paulo: CEDEC, n.17, p.49-66, jun. 1989. Disponível em: $<$ http://www.scielo.br/scielo.php?script=sci_arttext\&pid=S0102-64451989000200004> Acesso em: 13 set 201.

MENDONÇA, Ricardo Fabrino. Reconhecimento e Deliberação: as lutas das pessoas atingidas pela hanseníase em diferentes âmbitos interacionais. 369 f. Tese (Doutorado em Comunicação Social) - Faculdade de Filosofia e Ciências Humanas, UFMG, Belo Horizonte, 2009.

NARVAZ, Martha Giudice; KOLLER, Sílvia Helena. Famílias e patriarcado: da prescrição normativa à subversão criativa. Psicologia \& Sociedade, Porto Alegre, RS, v. 18, n. 1, p. 49- 
55, jan/abr. 2006. Disponível em: < http://www.scielo.br/pdf/psoc/v18n1/a07v18n1> . Acesso em: 13 set. 2019.

SCHERER-WARREN, Ilse. Das mobilizações às redes de movimentos sociais. Sociedade e Estado, v. 21, n. 1, p. 109-130, jan./abr. 2006. Dossiê: Movimentos sociais. Disponível em: < http://www.scielo.br/pdf/se/v21n1/v21n1a07> . Acesso em: 13 set. 2019.

SIMÕES, Júlio; FACCHINI, Regina. Na trilha do arco-íris: do movimento homossexual ao LGBT. São Paulo: Perseu Abramo, 2009.

VIZER, Eduardo A. Movimentos Sociais: novas tecnologias para novas militâncias. In: VICENTE, Maximiliano Martin. (Org.) Mídia e sociedade - perspectivas. São Paulo: Canal 6, 2007, p. 9- 30 . 